\title{
Costos de calidad como estrategia de gestión en el central azucarero Trujillo, S.A., Venezuela*
}

Cost of quality as a management strategy in The Central Azucarero Trujillo, S.A., Venezuela Custos de qualidade como estratégia de gestão na central açucareira Trujillo, S.A., Venezuela

Morelia Montilla ${ }^{\mathrm{a}}$

Universidad de Los Andes, Venezuela

moreestudios@hotmail.com

ORCID: http://orcid.org/0000-0001-6477-9234

Stephania Alizo

Universidad de Los Andes, Venezuela

ORCID: http://orcid.org/0000-0001-6610-9242

Diyerson Salazar

Universidad de Los Andes, Venezuela

ORCID: http://orcid.org/0000-0001-6518-4697

\author{
Nellitza Rivas \\ Universidad de Los Andes, Venezuela \\ ORCID: http://orcid.org/0000-0002-7757-3662
}

\section{Resumen:}

El propósito de esta investigación es construir una aproximación teórica que relacione los costos de calidad con las estrategias de gestión en el Central Azucarero Trujillo S.A., Venezuela. Para tal fin, se realizó un estudio descriptivo con diseño de campo. Para la recolección de la información se utilizó la entrevista estructurada, validada por tres expertos. Los resultados fueron analizados con matrices de triangulación. Se concluye que la entidad incurre en costos de calidad, destacando los de prevención y evaluación, tienen establecidas estrategias orientadas al mejoramiento continuo de la entidad; no obstante, se evidencia la falta de consideración de la información suministrada por los costos de calidad en el establecimiento de estrategias de gestión. Se propone una matriz que facilite comprender la participación que pueda generar cada una de las categorías de los costos de calidad con respecto a las estrategias de gestión llevadas a cabo en el Central Azucarero Trujillo S.A., con el propósito de fortalecer su productividad y operatividad.

Código JEL: M11.

Palabras clave: Costos de calidad, estrategia de gestión, Central Azucarero Trujillo, S.A.

\section{Abstract:}

The purpose of this research was to construct a theoretical approach that links quality costs with the management strategies at Central Azucarero Trujillo, S.A. For this purpose, a descriptive study with field design was carried out. For the collection of the information, a structured interview was used and validated by three experts. The results were analyzed using triangulation matrices, performing a content analysis. It is concluded that the entity incurs quality costs -highlighting those of prevention and evaluation- have established strategies oriented to the continuous improvement of the entity. However, there is evidence of the lack of consideration of the information provided by the quality costs in the establishment of management strategies. A matrix is proposed that makes it easier to understand the participation that each one of the categories of quality costs can generate regarding the management strategies carried out at the Central Azucarero Trujillo, S.A., with the purpose of strengthening its productivity and operability.

JEL Code: M11.

Keywords: Quality costs, management strategy, Central Azucarero Trujillo, S.A..

Notas de autor:

a Autora de correspondencia. Correo electrónico: moreestudios@hotmail.com 
Resumo:

O objetivo desta pesquisa é construir uma abordagem teórica que relacione os custos de qualidade às estratégias de gestão na Central Açucareira Trujillo S.A., Venezuela. Para tanto, foi realizado um estudo descritivo com pesquisa de campo. A entrevista estruturada, validada por três especialistas, foi utilizada para coletar as informações. Os resultados foram analisados com matrizes de triangulação. Conclui-se que a entidade incorre em custos de qualidade, destacando os de prevenção e avaliação, e tem estabelecidas estratégias visando à melhoria contínua da entidade; no entanto, fica evidenciada a falta de consideração das informações fornecidas pelos custos de qualidade no estabelecimento de estratégias de gestão. É proposta uma matriz que facilite o entendimento da participação que cada uma das categorias de custos de qualidade em relação às estratégias de gestão realizadas na Central Açucareira Trujillo S.A., com o objetivo de fortalecer sua produtividade e operacionalidade.

Código JEL: M11.

Palavras-chave: custos de qualidade, estratégia de gestão, Central Açucareira Trujillo, S.A.

\section{INTRODUCCIÓN}

En la actualidad las entidades se encuentran inmersas en una dinámica económica cambiante, en la que tanto los factores internos (costos de materia prima, mano de obra, costos indirectos, costos de los procesos y procedimientos), como los factores externos (cambios políticos, económicos, sociales y tecnológicos), intervienen en la productividad resultante de sus operaciones. En tal sentido, las entidades deben garantizar su rendimiento mediante estrategias de gestión, siendo de principal aplicación en las entidades manufactureras, puesto que deben centrarse en el mejoramiento continuo de toda la cadena de valor de los productos, para poder determinar precios que permitan la captación de gran parte del mercado.

Dentro de estas estrategias se encuentra la gestión de la calidad cuyo propósito es coordinar el esfuerzo de toda la entidad para mejorar, tanto la calidad como la productividad, mediante la aplicación de un conjunto de estrategias encaminadas a obtener resultados que optimicen los procesos. En concordancia, la Organización Internacional de Normalización (ISO) 9000:2015 (2015, p. 39), señala que la gestión de la calidad está conformada por actividades coordinadas para dirigir y controlar la calidad en las entidades, contando con cuatro componentes: planeamiento de la calidad, control de la calidad, aseguramiento de la calidad y mejoras en la calidad.

Dentro de los sistemas de gestión de calidad se debe resaltar la importancia que tienen los costos de calidad, ya que según Ramírez (2013, p. 517), son "costos que se relacionan con la creación, identificación, reparación y prevención de defectos". Es decir, los costos de calidad muestran detalladamente los desembolsos originados por la obtención y aseguramiento de una calidad satisfactoria, de igual manera permiten conocer las pérdidas que se pueden obtener en caso de no alcanzar los resultados previstos en cuanto al logro del cumplimiento de los estándares predeterminados.

En Venezuela, las entidades manufactureras están siendo impactadas por el actual contexto económico, político y social. La dependencia económica de la actividad petrolera, junto con la caída en el precio del barril del crudo, causan reducción en los ingresos en dólares y aumento en la demanda de la divisa. Esto afecta la actividad productiva del país, por cuanto la mayor parte de los insumos son importados. Si bien se ha procurado sustituir insumos, esto no asegura la calidad de los productos ofrecidos.

En el estado Trujillo existen múltiples entidades manufactureras dedicadas a la transformación de, por ejemplo, productos agroindustriales, alimentos para animales, envases de vidrio y de plástico, etc. Dentro del sector agroindustrial se encuentra el Central Azucarero Trujillo S.A., ubicada en Motatán Estado Trujillo, dedicada a la transformación de caña de azúcar y refinación de azúcar, entidad que requiere el manejo de sistemas de control y aseguramiento de la calidad como estrategia de gestión, para satisfacer las necesidades de los clientes, manteniendo bajos costos en sus productos o servicios y, a su vez, una alta calidad, evitando la presencia de desperfectos, fallas o desperdicios que se pudieran generar.

Mediante una entrevista de diagnóstico realizada por los investigadores al encargado de mantenimiento y seguridad y, al encargado de laboratorio de procesos del Central Azucarero Trujillo, S.A., se constató que la entidad mantiene un control de calidad antes, durante y después del proceso productivo. Sin embargo, aun 
cuando existe un manual formal de políticas y normas de calidad, se han visto en la necesidad de ajustar esos controles de calidad, más en el conocimiento general y experiencia de quienes trabajan en producción que en las normas propiamente establecidas.

Ambos entrevistados aseguran que el proceso comienza en el campo de siembra de la caña de azúcar, debido a que existen factores ambientales que pueden afectar la cosecha y generar bajo rendimiento en la producción. Dentro de los factores ambientales se puede mencionar la presencia de lluvias, provocando que el proceso de fotosíntesis no se lleve a cabalidad durante épocas de invierno y genere baja concentración de azúcar en la planta.

En el Central Azucarero Trujillo S.A. han tenido que detener los procesos productivos por falta de insumos, principalmente la falta de la caña de azúcar, originado por condiciones meteorologías y también económicas, debido a la escasez de insumos agrícolas que han contribuido a la baja producción de caña de azúcar en la entidad trujillana.

Por otra parte, durante la entrevista de diagnóstico se pudo conocer que el Central Azucarero Trujillo S.A., adicionalmente trabaja con materia prima semi-elaborada, es decir, granos de azúcar traída de otros países, sin la certeza de la debida verificación de los controles de calidad aptos para este tipo de insumo, como también el desconocimiento de políticas de higiene acordes para el transporte de la materia prima, desde el país de embarque hasta la planta del Central Azucarero Trujillo S.A., prácticas adoptadas como medidas de emergencia para cubrir la demanda de azúcar en el Estado Trujillo.

En consecuencia, si la entidad no mantiene un control de gestión efectivo de sus costos de calidad y, al no basar sus procesos en políticas de calidad formales, se podría poner en riesgo el cumplimiento de los estándares de calidad del producto. Además, se observa un desajuste conceptual en las estrategias de gestión porque los fundamentos teóricos no incluyen los costos de calidad. Lo anterior podría conducir a perder la capacidad de conocer si la inversión realizada está generando los resultados esperados en términos de disminución de los costos y aumento de la productividad.

Dentro de esta realidad se hace necesario para el Central Azucarero Trujillo S.A., poner en práctica políticas de calidad encaminadas a obtener una mejora continua de los procesos productivos y, por ende, lograr la satisfacción plena de los clientes. De igual manera, deben velar por lograr altos estándares de calidad, mediante estrategias de gestión que contribuyan al aumento de la productividad del Central Azucarero Trujillo S.A., manteniendo clientes satisfechos y logrando el abastecimiento de los anaqueles del Estado Trujillo y por consiguiente, los del país.

Por lo antes expuesto, resulta interesante desarrollar un estudio que permita construir una aproximación teórica que relacione los costos de calidad con las estrategias de gestión en el Central Azucarero Trujillo S.A., proporcionando de esta manera la comprensión necesaria sobre la importancia de la aplicación de políticas de calidad formales, así como la capacidad de contar con estrategias de gestión orientadas a la proyección de dicha entidad en el mediano y largo plazo.

El desarrollo del artículo comienza con la revisión de literatura de los costos de calidad y de las estrategias de gestión, enseguida presenta la aproximación teórica de los costos de calidad como estrategias de gestión en el Central Azucarero Trujillo, S.A. Posteriormente se expone la metodología y los resultados, dentro de los cuales se destaca la elaboración de una matriz explicativa que relaciona el impacto de los costos de calidad con las estrategias de gestión en el Central Azucarero Trujillo, S.A., y que potencializa la toma de decisiones de la empresa. El documento cierra con la exposición de las conclusiones y recomendaciones de la investigación.

\section{REVISIÓN DE LITERATURA}

En un principio, en las entidades manufactureras la calidad estaba orientada hacia la producción, considerando sólo el grado en que un producto cumplía con los parámetros establecidos en su diseño; en 
la actualidad este concepto ha venido evolucionando considerando, además del cumplimiento del producto de sus especificaciones de diseño, el grado en que satisface las necesidades y expectativas de sus clientes, empleados, accionistas y sociedad. En este sentido, la Sociedad Americana para la Calidad (2017), la definen como la totalidad de rasgos y características de un producto o un servicio dado de acuerdo con ciertas especificaciones, para satisfacer a los clientes, al tiempo de la compra y durante el uso.

Horngren, Datar y Foster (2007, p. 677) se refieren a los costos de calidad como "los costos en que se incurren para la prevención o, los costos que surgen como resultado de la producción de baja calidad de un producto". Por su parte, Cuervo (2000), destaca que los costos de calidad están relacionados con la definición, creación y control de la calidad, así como la evaluación de la conformidad con la calidad y los asociados con las consecuencias de no cumplir los requisitos o exigencias de calidad, tanto dentro de la fábrica como en manos de los clientes.

Para Dale y Plunkett (1993), Polimeni, Fabozzi, Adelberg, \& Kole (1994), Horngren, Datar y Foster (2007), los costos de calidad se dividen en cuatro categorías (ver figura 1).

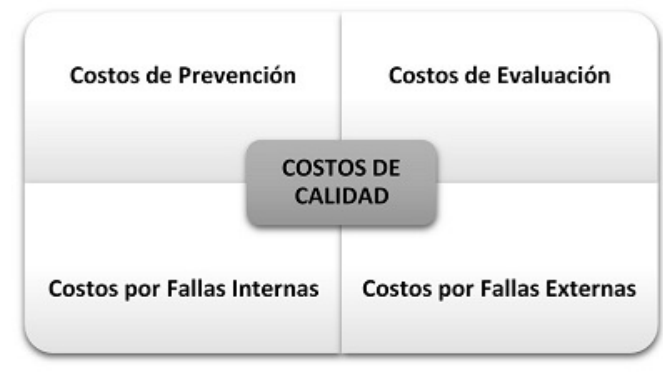

FIGURA 1

Clasificación de los costos de calidad

elaboración propia con base en Dale y Plunkett (1993), Pollimeni et al. (1994), Horngren et al. (2007)

- Costos de prevención: son aquellos en que se incurre para evitar la fabricación de productos que no estén apegados a las especificaciones, representan el costo de todas las actividades llevadas a cabo para evitar problemas desde el inicio de un producto o servicio, hasta su comercialización.

- Costos de evaluación: son los que tienen como finalidad detectar las imperfecciones en los productos que por una u otra razón no se apegaron a las especificaciones; proceden de actividades de inspección, pruebas y evaluaciones que se han planeado para determinar el cumplimiento de los requisitos establecidos.

- Costos por fallas internas: son los que agrupan todos los costos causados una vez finalizado el proceso productivo, pero en cuyo caso el producto no ha sido entregado al cliente, se relacionan con los defectos que aparecen en el proceso productivo y que ameritan descarte o reprocesamiento del producto.

- Costos por fallas externas: son los que se originan cuando, una vez suministrado el producto o servicio al consumidor, este es inaceptable por no cumplir con las especificaciones requeridas, esto puede traer como consecuencia la pérdida de clientes debido a la insatisfacción que genere el producto o servicio.

Otros autores, como Arango (2009), prefieren clasificar estas categorías en costos de calidad y no calidad, entendiendo los costos de calidad como aquellos en los que la entidad incurre para optimizar el producto, tales como los costos de prevención y evaluación; y costos de no calidad, como aquellos que no son necesarios en el proceso productivo y que generalmente son elevados por causas de fallas internas y externas.

Según Vesga (2013), la calidad debe ser gestionada en las entidades, porque ésta no puede alcanzarse por sí misma, sino que requiere de procedimientos aplicados fundamentados en una cultura organizacional. En este sentido, la gestión de la calidad puede definirse como un conjunto de variables que se relacionan para la mejora de la calidad. Esta concepción puede complementarse con lo apuntado por Betancourt (2002), y Chase y Jacobs (2014). 
Betancourt (2002, p. 106), señala que la estrategia de gestión consiste en "el arte y/o ciencia de anticipar y gerenciar participativamente el cambio con el propósito de crear permanentemente estrategias que permitan garantizar el futuro del negocio". Por lo tanto, la estrategia de gestión permite a las entidades mantener una mejora continua de sus operaciones con la finalidad de lograr principalmente la satisfacción de sus clientes, ofreciendo productos de calidad a bajos precios; para ello cualquier entidad y en especial las manufactureras deben manejar una gestión de calidad que abarque todas sus operaciones, desde antes de la compra de materia prima hasta después de la venta del producto.

Los estudios de Chase y Jacobs (2014), Marbán (2005) y Hernández, Barrios y Martínez (2018), profundizan lo señalado por Betancourt (2002), al destacar que dentro de las estrategias de gestión se pueden mencionar las siguientes:

- Estrategia de operaciones y cadena de suministros. Se ocupa de establecer las políticas y planes para utilizar los recursos de una entidad, debe estar integrada a la estrategia corporativa, siendo uno de los principales propósitos dentro de esta estrategia, la eficacia de las operaciones.

- Eficacia de las operaciones. Se relaciona con los procesos financieros esenciales para que opere la entidad (tomar pedidos de clientes, devoluciones, manufacturas y administrar la actualización de la página web hasta enviar productos a su destino).

- Estrategia de costo o precio. "Fabricar el producto o vender el servicio con un precio barato". Por lo general un grupo del mercado global se dedica a la compra de productos a bajos precios, en tal sentido, la entidad debe ser un productor con costos bajos, aunque esto no siempre garantice rentabilidad elevada.

- Estrategia de calidad. "Fabricar un producto excelente o brindar un producto excelente". Existen dos características esenciales que determinan la calidad de un producto o servicio, ellas son: a) calidad del diseño: se relaciona con el conjunto de características que contiene el producto o servicio; los clientes consideran que los productos con un diseño excesivo y los servicios con características inapropiadas y en demasía son prohibitivamente caros. b) calidad del proceso: se relaciona directamente con la confiabilidad del producto o servicio. En tal sentido, la meta de la calidad de proceso es producir bienes y servicios sin defectos.

- Estrategia de velocidad de la entrega. "Fabricar el producto o brindar el servicio con rapidez". Esta estrategia es fundamental dentro de las entidades debido a que mientras más rápido se fabrique y entregue el producto mayor será la satisfacción del cliente, lo que conllevaría al aumento de la productividad dentro de la entidad.

- Estrategia de confiabilidad en entrega. "Entregar conforme a lo prometido". Está estrechamente ligada a la capacidad que tiene la entidad de suministrar el producto o servicio en la fecha de entrega prometida o antes.

- Estrategia para afrontar los cambios de la demanda. "Alterar el volumen". Es de gran importancia la capacidad de respuesta que posee la entidad para responder a las variaciones de la demanda. En cuanto al incremento de la demanda, los costos disminuyen en forma continua en razón de las economías de escala; por su parte, el decremento de la demanda puede requerir muchas decisiones difíciles dentro de la entidad, como por ejemplo: despedir personal y reducir otros activos.

- Estrategia de flexibilidad y velocidad para introducir nuevos productos. "Cámbielo". La flexibilidad se refiere a la capacidad que tiene la entidad para ofrecer una amplia variedad de productos a sus clientes, siendo el tiempo un elemento muy importante y necesario para desarrollar un nuevo producto y transformar sus procesos a efecto de ofrecer un nuevo producto.

- Otros criterios específicos del producto. "Apóyelo". En las entidades manufactureras principalmente, no sólo deben dedicarse a transformar materia prima para cumplir con las especificaciones de un producto, también deben brindar actividades de apoyo que aumente la satisfacción de los clientes y por ende apoyen al fortalecimiento de la productividad de la entidad, entre las cuales se pueden mencionar: enlace y apoyo técnico; apoyo postventa del proveedor; impacto ambiental. 


\section{APROXIMACIÓN TEÓRICA}

Esta aproximación de los costos de calidad como estrategia de gestión se fundamentó en relacionar los tipos de costos de calidad (prevención, evaluación, fallas internas y fallas externas) con las diferentes estrategias de gestión (operaciones y cadenas de suministros, costo o precio, calidad, velocidad de entrega, confiabilidad de entrega, afrontar cambios en la demanda, flexibilidad y velocidad para introducir nuevos productos, y finalmente, criterios específicos del producto), en un contexto específico, como lo es el Central Azucarero Trujillo, S.A. Ver tabla 1.

TABLA 1_1

Impacto de los costos de calidad en las estrategias de gestión en el Central Azucarero Trujillo, S.A

\begin{tabular}{|c|c|c|c|c|}
\hline $\begin{array}{l}\text { CATEGORIAS DE } \\
\text { LOS COSTOS } \\
\text { DE CALIDAD }\end{array}$ & COSTOS DE PREVENCIÓN & CosTos dE EVALUACIÓN & $\begin{array}{l}\text { COSTOS POR FALLAS } \\
\text { INTERVAS }\end{array}$ & $\begin{array}{l}\text { COSTOS POR FALLAS } \\
\text { EXTERVAS }\end{array}$ \\
\hline $\begin{array}{l}\text { ESTRATEGLA DE } \\
\text { OPERACIONES Y CADENA DE } \\
\text { SUMNISTROS }\end{array}$ & $\begin{array}{l}\text { Permiten el mejor } \\
\text { aprovecham ianto de los recursos } \\
\text { de la entidad, siendo prim ordial } \\
\text { la planificacióe de las } \\
\text { actividades a llevar a cabo en los } \\
\text { procesos prodactivos. Por otro } \\
\text { bdo, se obtiette el } \\
\text { fortalecimiento de los sistemas } \\
\text { de costos de calidad. }\end{array}$ & $\begin{array}{l}\text { Los costos de evaluación se } \\
\text { podrina ser como un proceso de } \\
\text { retroalimentación para la } \\
\text { entidad, porque permiten } \\
\text { detectar las imperfecciones que } \\
\text { se pudieran estar presentando. A } \\
\text { su vec, esto permite el } \\
\text { mejoramiento de las operaciones } \\
\text { y de la cadena de saministros. }\end{array}$ & $\begin{array}{l}\text { Masteniendo un riguroso control } \\
\text { de las operaciones del proceso } \\
\text { productivo se pueden evitar } \\
\text { cualquier tipo de fallas. Por lo } \\
\text { tanto, los gerentes deben vigilar y } \\
\text { evitar el uso excesivo de materiales } \\
\text { y suministros, asi como también } \\
\text { desperdician gum inistros o inclaso } \\
\text { evitar que los productos sean } \\
\text { teprosesados. }\end{array}$ & $\begin{array}{l}\text { El mal uso de los suministros o el } \\
\text { control errado de las operaciones } \\
\text { puede hacer que las quejas por parte } \\
\text { de los clientes sean elevadas, esto } \\
\text { traeria como resultado la pérdida de } \\
\text { clisutes y uta cadia de las ventas. En } \\
\text { consecuencia, las estrategias de } \\
\text { operacion y cadena de suministros } \\
\text { deben asegurar que los procesos se } \\
\text { lleven a cabalidad. }\end{array}$ \\
\hline $\begin{array}{l}\text { ESTRATEGLA DE COSTO O } \\
\text { PRECIO }\end{array}$ & $\begin{array}{l}\text { A través de la planificación de } \\
\text { las actividades a Levar a cabo, se } \\
\text { puede prerenir errores o } \\
\text { desperfectos en los productos o } \\
\text { servicios, lo que generaria bajos } \\
\text { costos de producción y por ende } \\
\text { alcanzaria un precio óptimo de } \\
\text { venta. }\end{array}$ & $\begin{array}{l}\text { A pesar que los costos de } \\
\text { evaluación permiten el } \\
\text { mejoram iento continuo de la } \\
\text { entidad, estos no pueden ser } \\
\text { exageradiam ente allos, por lo } \\
\text { tanto, se deben llevar a cabo } \\
\text { inspecciones o anditorias que } \\
\text { aporten la mayor cantidad de } \\
\text { infomación para la toma de } \\
\text { decisiones, de mantera tal que los } \\
\text { costos de producción no sean tan } \\
\text { elersdos y se poeda ofrecer } \\
\text { productos a bajos costos. }\end{array}$ & $\begin{array}{l}\text { Los costos de producción podrian } \\
\text { verse afectados cuando no se llevan } \\
\text { a cabo los procesos acordes a las } \\
\text { especificaciones requeridas. Los } \\
\text { reprosesos o desperdicios } \\
\text { principalmente aum entan el costo } \\
\text { de los productos y por ende evita la } \\
\text { fijación de precios óptimos de } \\
\text { venta. En este sentido, se debe } \\
\text { realizar el trabajo de la m ejor } \\
\text { masnera posibje evitando el sumento } \\
\text { de los costos de prodacción. }\end{array}$ & 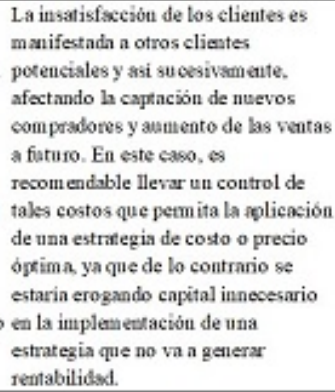 \\
\hline ESTRATEGLA DE CALIDAD & 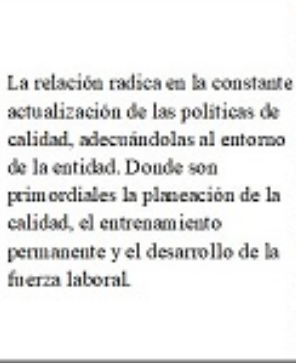 & $\begin{array}{l}\text { Los costos de calidsd apoyat la } \\
\text { toma de decisiones, debido a que } \\
\text { a traves de los procesos de } \\
\text { maditoria de los sistemas } \\
\text { operativos se pueden detectar } \\
\text { desaiveles en los readimientos } \\
\text { de la calidad de los productos, } \\
\text { conde uno de los principales } \\
\text { factores que atribuyen los } \\
\text { desaiveles es la calidad de la } \\
\text { manteria prima e incluso su } \\
\text { tratamiento, lo cual afecta la } \\
\text { satisfacsion de los clientes. }\end{array}$ & 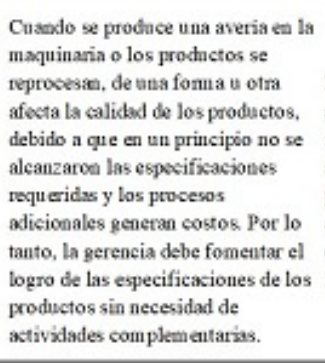 & $\begin{array}{l}\text { La eslidad de los productos se ve } \\
\text { afoctada hasta por la mias mininial } \\
\text { falla que se presente, mis aun cuando } \\
\text { ge hacen servicios por garaetia el } \\
\text { producto va perdiendo el valor } \\
\text { ayregado, debido a que no ba } \\
\text { camplido con los reguerimientos de } \\
\text { los clientes. }\end{array}$ \\
\hline
\end{tabular}

Fuente: elaboración propia con base en Horngren et al. (2007), Vesga (2013), Cuervo (2000), Dale y Plunkett (1993), Polimeni et al. (1994), Betancourt (2002) y Chase y Jacobs (2014). 
TABLA 1_2

Impacto de los costos de calidad en las estrategias de gestión en el Central Azucarero Trujillo, S.A

\begin{tabular}{|c|c|c|c|c|}
\hline $\begin{array}{l}\text { CATEGORIAS DE } \\
\text { ESTRATEGIAS } \\
\text { DE GESTIOS }\end{array}$ & COSTOS DE PREVENCIÓN & COSTOS DE EVALUACIÓN & $\begin{array}{l}\text { COSTOS POR FALLAS } \\
\text { INTERNAS }\end{array}$ & $\begin{array}{c}\text { COSTOS POR FALLAS } \\
\text { EXTERNAS }\end{array}$ \\
\hline $\begin{array}{l}\text { ESTRATEGIA DE VELOCTDAD DE } \\
\text { LA ENTREGA }\end{array}$ & 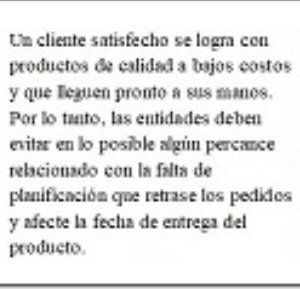 & 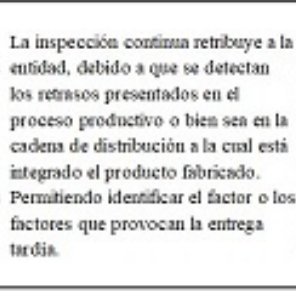 & 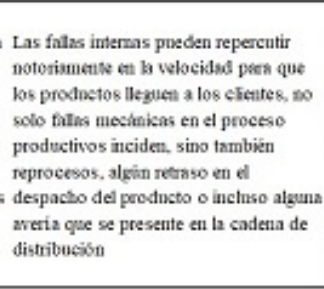 & 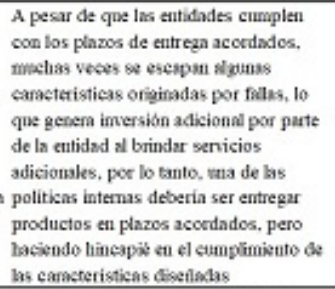 \\
\hline $\begin{array}{l}\text { ESTRATEGIA DE CONFIABILIDAD } \\
\text { EN ENTREGA }\end{array}$ & 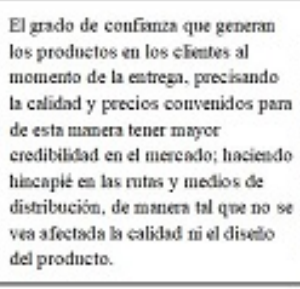 & 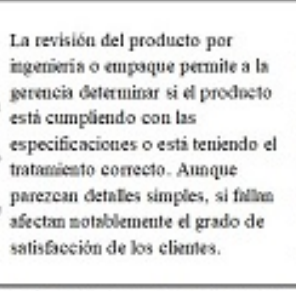 & 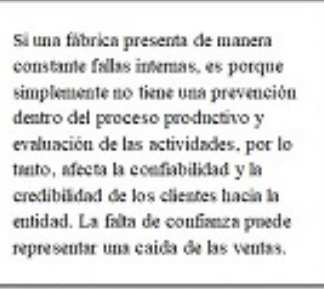 & 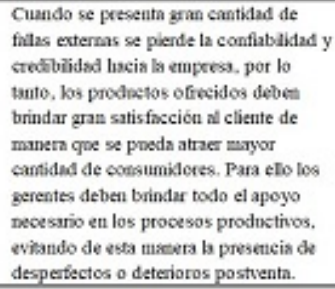 \\
\hline $\begin{array}{l}\text { ESTRATEGIA PARA AFRONTAR } \\
\text { LOS CAMBIOS EN LA DEMLANDA }\end{array}$ & 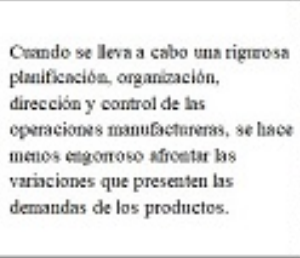 & 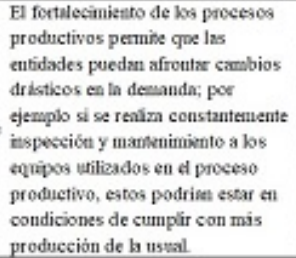 & 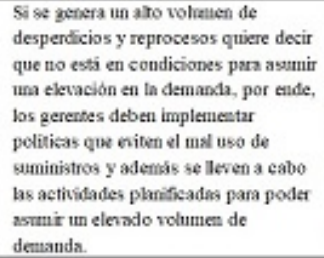 & 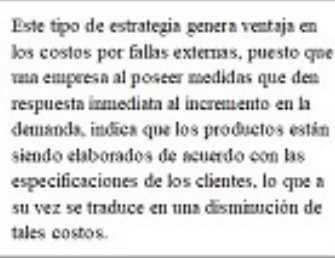 \\
\hline
\end{tabular}

Fuente: elaboración propia con base en Horngren et al. (2007), Vesga (2013), Cuervo (2000),

Dale y Plunkett (1993), Polimeni et al. (1994), Betancourt (2002) y Chase y Jacobs (2014). 
TABLA 1_3

Impacto de los costos de calidad en las estrategias de gestión en el Central Azucarero Trujillo, S.A

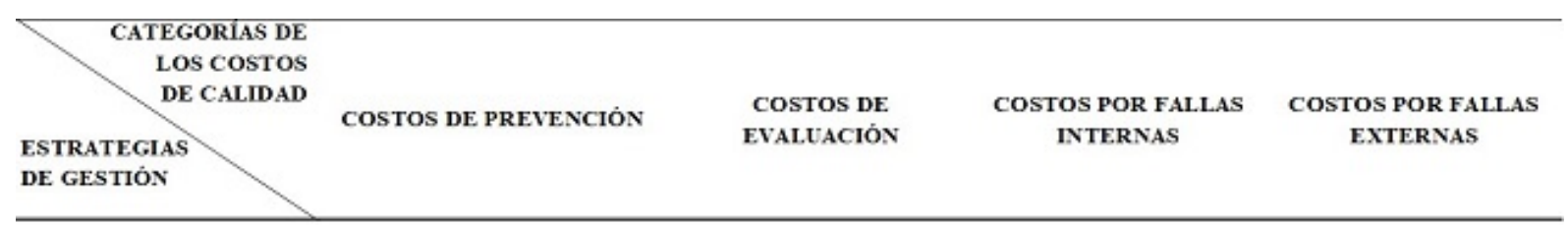

\begin{tabular}{|c|c|c|c|c|}
\hline $\begin{array}{l}\text { ESTRATEGIA DE } \\
\text { FLEXIBIIDAD Y } \\
\text { VELOCIDAD PARA } \\
\text { INTRODUCIR NUEVOS } \\
\text { PRODUCTOS }\end{array}$ & $\begin{array}{l}\text { Las entidades no deben pasar por alto } \\
\text { ningiun detalle que coadyuve al } \\
\text { impulso y fortalecimiento de los } \\
\text { sistemas operativos de las entidades. } \\
\text { Así, será más factible introducir la } \\
\text { fabricación de nuevos productos sin } \\
\text { afectar el funcionamiento. } \\
\text { Principalmente el desamollo y } \\
\text { entrenamiento continuo de la fuerza } \\
\text { laboral contribuye a que estos se } \\
\text { adhieran más raipido a los cambios en } \\
\text { los procesos. }\end{array}$ & $\begin{array}{l}\text { En el caso de no realizar } \\
\text { seguimiento a los procesos } \\
\text { productivos, la entidad podría } \\
\text { no estar preparada para la } \\
\text { introducción de nuevas lineas } \\
\text { de productos, aun cuando se } \\
\text { tenga una buena planificación } \\
\text { las inspecciones y auditorias } \\
\text { son puntos claves que } \\
\text { permiten tener un conocimiento } \\
\text { más amplio de las condiciones } \\
\text { operativas. }\end{array}$ & $\begin{array}{l}\text { Para toda entidad es un reto } \\
\text { introducir nuevos productos al } \\
\text { mercado; para lograrlo los } \\
\text { procesos productivos deben } \\
\text { ser transparentes, evitando } \\
\text { cuakquier desperfecto o falla } \\
\text { que pueda generar un bloqueo } \\
\text { en la fabricación. Se deben } \\
\text { disminuir las fallas internas en } \\
\text { la mayor cantidad posible. } \\
\text { fortaleciendo los procesos } \\
\text { productivos a través de la } \\
\text { prevención y evaluación de } \\
\text { incidencias. }\end{array}$ & $\begin{array}{l}\text { Una vez que se incurre en } \\
\text { costos por fallas externas, es } \\
\text { inportante que la empresa } \\
\text { cuente con la capacidad de } \\
\text { incorporar nuevos productos } \\
\text { que logren satisfacer los } \\
\text { requerimientos de los clientes } \\
\text { en un tiempo de elaboración y } \\
\text { entrega pertinente, lo que } \\
\text { conllevará a la misma a la } \\
\text { recuperación de los costos } \\
\text { generados adicionalmente. }\end{array}$ \\
\hline $\begin{array}{l}\text { OTROS CRITERIOS } \\
\text { ESPECIFICOS DEL } \\
\text { PRODUCTO }\end{array}$ & $\begin{array}{l}\text { Las operaciones de las entidades } \\
\text { mamufactureras no sólo se deben } \\
\text { basar en la transformación de materia } \\
\text { prima, sino que además deben } \\
\text { planificar la implementación de } \\
\text { actividades de apoyo a las } \\
\text { operaciones y el producto (p. ej., } \\
\text { servicios postventa para conocer las } \\
\text { expectativas de los clientes en cuanto } \\
\text { al producto obtenido). }\end{array}$ & $\begin{array}{l}\text { Aun cuando una entidad cuente } \\
\text { con los mejores especialistas } \\
\text { para la defección de cualquier } \\
\text { operación errada, cabe la } \\
\text { probabilidad de que alguin } \\
\text { producto no esté acorde a las } \\
\text { especificaciones establecidas. } \\
\text { Por ello es de gran importancia } \\
\text { contar con actividades de } \\
\text { apoyo postventa que detecten } \\
\text { algín error percibido durante el } \\
\text { uso del producto. }\end{array}$ & $\begin{array}{l}\text { Las actividades de apoyo a la } \\
\text { fabricación del producto } \\
\text { ayudiarian a conocer cualquier } \\
\text { detalle que se haya pasado por } \\
\text { alto en el proceso de auditoria } \\
\text { del producto. Alli radica la } \\
\text { importancia de contar con } \\
\text { actividades postventa que } \\
\text { atribuysan el fortalecimiento de } \\
\text { los procesos productivos en } \\
\text { una visión de mejora y } \\
\text { crecimiento continuo. }\end{array}$ & $\begin{array}{l}\text { Los servicios postventa } \\
\text { dirigidos hacia los clientes para } \\
\text { conocer sus inquietudes o } \\
\text { sugerencias, son de gran } \\
\text { importancia porque permite } \\
\text { eliminar erogaciones de capital } \\
\text { que se pudieran presentar } \\
\text { durante el proceso productivo, } \\
\text { porque se inplementarian } \\
\text { estrategias que eliminarian en } \\
\text { la mayor cantidad posible las } \\
\text { fallas que se pudieran } \\
\text { presentar, logrando la } \\
\text { purificación de los procesos, } \\
\text { con miras al crecimiento } \\
\text { productivo }\end{array}$ \\
\hline
\end{tabular}

Fuente: elaboración propia con base en Horngren et al. (2007), Vesga (2013), Cuervo (2000),

Dale y Plunkett (1993), Polimeni et al. (1994), Betancourt (2002) y Chase y Jacobs (2014).

\section{MARCO METODOLÓGICO}

Luego de hacer un diagnóstico y determinar la problemática de la investigación se realizó la siguiente pregunta: ¿Cómo es la construcción de una aproximación teórica que relacione los costos de calidad con las estrategias de gestión en el Central Azucarero Trujillo, S.A.? Para lo cual los investigadores se plantearon las tareas de investigación registradas en la tabla 2. 
TABLA 2

Matriz de dimensiones y ejes de indagación

\begin{tabular}{|c|c|c|c|}
\hline Tareas de investigación & Propósitos & $\begin{array}{l}\text { Dimensiones } \\
\text { indagadoras }\end{array}$ & Ejes de indagación \\
\hline $\begin{array}{l}\text { ¿Cuáles son los costos de } \\
\text { calidad aplicados en el } \\
\text { Central Azucarero Trujillo } \\
\text { S.A.? }\end{array}$ & $\begin{array}{l}\text { Describir los costos de } \\
\text { calidad aplicados en el } \\
\text { Central Azucarero } \\
\text { Trujillo, S.A. }\end{array}$ & Costos de calidad & $\begin{array}{l}\text { - Costos de } \\
\text { prevención } \\
\text { evaluación Costos de } \\
\text { - Costos por fallas } \\
\text { internas } \\
\text { - Costos por fallas } \\
\text { externas }\end{array}$ \\
\hline $\begin{array}{l}\text { ¿Cuáles son las estrategias } \\
\text { de gestión aplicadas en el } \\
\text { Central Azucarero Trujillo } \\
\text { S.A.? }\end{array}$ & $\begin{array}{l}\text { Determinar las estrategias } \\
\text { de gestión aplicadas en el } \\
\text { Central Azucarero } \\
\text { Trujillo, S.A. }\end{array}$ & Estrategias de gestión & $\begin{array}{l}\text { - } \\
\text { opstrategias de } \\
\text { suministros. } \\
\text { - } \quad \text { Estrategia de } \\
\text { costo o precio. } \\
\text { - Estrategia de } \\
\text { calidad. } \\
\text { - } \quad \text { Estrategia de } \\
\text { velocidad en entrega. }\end{array}$ \\
\hline $\begin{array}{l}\text { ¿Cuál es la relación entre } \\
\text { los costos de calidad y las } \\
\text { estrategias de gestión en el } \\
\text { Central Azucarero Trujillo, } \\
\text { S.A.? }\end{array}$ & $\begin{array}{l}\text { Analizar la relación entre } \\
\text { los costos de calidad y las } \\
\text { estrategias de gestión en el } \\
\text { Central Azucarero } \\
\text { Trujillo, S.A }\end{array}$ & \multicolumn{2}{|c|}{$\begin{array}{l}\text { Ver tabla 1. Propuesta de la investigación, planteada } \\
\text { en el marco teórico y en las recomendaciones de la } \\
\text { investigación. Esta propuesta está fundamentada en } \\
\text { los análisis de los resultados y en los aportes de los } \\
\text { autores: Horngren et al. (2007), Cuervo (2000), Dale } \\
\text { y Plunkett (1993), Polimeni et al. (1994), Betancourt } \\
\text { (2002) y Chase y Jacobs (2014). }\end{array}$} \\
\hline
\end{tabular}

Fuente: elaboración propia

De acuerdo con lo planteado, esta investigación se enmarca dentro de un estudio descriptivo, por cuanto su propósito fue construir una aproximación teórica que relacione los costos de calidad y las estrategias de gestión en el Central Azucarero Trujillo, S.A. Al respecto, Méndez (2013, p. 137) expresa que "los estudios descriptivos identifican características del universo de investigación, señala formas de conducta y actitudes del universo investigado, establece comportamientos concretos, y descubre y comprueba la asociación entre variables de investigación".

Esta investigación recurrió al diseño de campo, en el cual la recolección de datos se obtiene directamente de los sujetos investigados, o de la realidad donde ocurren los hechos, sin controlar variable alguna (Arias, 2012). Este diseño de campo se sustentó mediante entrevistas, técnica que consiste en realizar una conversación profesional con una o varias personas asociadas a un contexto específico para contribuir en diagnósticos y resultados. En este sentido, Arias (2012, p. 73) expresa que "la entrevista está basada en un diálogo o conversación cara a cara entre el entrevistador y el entrevistado acerca de un tema previamente determinado". Las entrevistas se realizaron en dos momentos metodológicos. En el primero, se realizó una entrevista diagnóstica semiestructurada (con guía de preguntas abiertas), la cual sirvió para conocer la problemática en el Central Azucarero Trujillo S.A, considerando como sujetos claves de información a la persona encargada de mantenimiento y seguridad, y a la persona encargada de laboratorio de procesos del Central Azucarero Trujillo S.A. Este primer acercamiento permitió visualizar la aproximación a una construcción teórica que relacione los costos de calidad y las estrategias de gestión en el Central Azucarero Trujillo, S.A. En la tabla 3 se presenta un resumen de la entrevista diagnóstica. 
TABLA 3

Entrevista en profundidad, fundamentadas en los ejes de indagación

\begin{tabular}{|c|c|c|c|}
\hline $\begin{array}{l}\text { Dimensiones de } \\
\text { indagación }\end{array}$ & Ejes de indagación & Ítems de indagación & Preguntas abiertas \\
\hline \multirow{4}{*}{$\begin{array}{l}\text { Costos de } \\
\text { calidad }\end{array}$} & $\begin{array}{l}\text { - Proceso } \\
\text { productivo }\end{array}$ & $\begin{array}{l}\text { - Etapas (inicio, desarrollo } \\
\text { y cierre) }\end{array}$ & $\begin{array}{l}\text { ¿En qué etapas del proceso productivo } \\
\text { son aplicados los costos de calidad en } \\
\text { el proceso productivo? }\end{array}$ \\
\hline & $\begin{array}{l}\text { - Costos de } \\
\text { evaluación }\end{array}$ & $\begin{array}{l}\text { - Herramientas } \\
\text { administrativas que } \\
\text { cvalúan la calidad en la } \\
\text { producción }\end{array}$ & $\begin{array}{l}\text { ¿Qué herramientas administrativas se } \\
\text { utilizan para garantizar un adecuado } \\
\text { costo de calidad? }\end{array}$ \\
\hline & $\begin{array}{l}\text { - Costos por } \\
\text { fallas internas }\end{array}$ & - Experiencia profesional & $\begin{array}{l}\text { ¿Cuál es el papel de la experiencia } \\
\text { profesional en los costos de calidad? }\end{array}$ \\
\hline & $\begin{array}{l}\text { - Costos por } \\
\text { fallas externas }\end{array}$ & $\begin{array}{l}\text { - Ambiente } \\
\text { - Impacto } \\
\text { económico/político }\end{array}$ & $\begin{array}{l}\text { ¿Cuáles costos son afectados por } \\
\text { variables externas a la organización? } \\
\text { ¿Cuál es el impacto de las variables } \\
\text { externas en los costos de calidad de la } \\
\text { producción? }\end{array}$ \\
\hline \multirow{4}{*}{$\begin{array}{l}\text { Estrategias de } \\
\text { gestión }\end{array}$} & $\begin{array}{l}\text { Estrategias } \\
\text { de operaciones y } \\
\text { cadenas de } \\
\text { suministros. }\end{array}$ & $\begin{array}{l}\text { - Obtención de la materia } \\
\text { prima } \\
\text { - Estándares de calidad de } \\
\text { la materia prima }\end{array}$ & ¿Cómo se obtiene la materia prima? \\
\hline & $\begin{array}{l}\text { - Estrategia de } \\
\text { costo o precio. }\end{array}$ & $\begin{array}{l}\text { - Proveedores de la materia } \\
\text { prima }\end{array}$ & $\begin{array}{l}\text { ¿Quićnes son los proveedores de la } \\
\text { materia prima? }\end{array}$ \\
\hline & $\begin{array}{l}\text { - Estrategia de } \\
\text { calidad. }\end{array}$ & $\begin{array}{l}\text { - Higiene } \\
\text { - Producto terminado }\end{array}$ & ¿Cuáles son las políticas de higiene? \\
\hline & $\begin{array}{l}\text { - Estrategia de } \\
\text { velocidad en entrega. }\end{array}$ & - Mercado abastecido & $\begin{array}{l}\text { ¿Cuáles son los clientes principales de } \\
\text { la entidad? } \\
\text { ¿Cuáles son los procedimientos para la } \\
\text { venta del producto? }\end{array}$ \\
\hline
\end{tabular}

Fuente: elaboración propia

En el segundo momento, se realizó una entrevista estructurada (guías de preguntas cerradas con respuestas que sustentan lo dicho por los sujetos informantes) para la medición de los resultados. Arias (2012, p. 73) define la entrevista estructurada como "una técnica basada en un dialogo o conversación cara a cara, entre el entrevistador y el entrevistado". De esta manera, la información se obtuvo directamente del Central Azucarero Trujillo, S.A., mediante entrevistas realizadas a los informantes clave que intervinieron en la investigación (ingeniero de seguridad industrial, ingeniero de control de calidad y el contador público de la entidad). En la tabla 4 se presenta un resumen de las preguntas realizadas en la entrevista estructurada, en conformidad con los ejes de indagación de la investigación. 
TABLA 4

Entrevista estructurada, fundamentadas en los ejes de indagación

\begin{tabular}{|c|c|c|}
\hline $\begin{array}{l}\text { Dimensiones de } \\
\text { indagación }\end{array}$ & Ejes de indagación & Preguntas \\
\hline \multirow{4}{*}{ Costos de calidad } & Costos de prevención & $\begin{array}{l}\text { Describa las categorias de costos de prevención que maneja } \\
\text { esta entidad en sus procesos de producción } \\
\text { a.- Planeación de la calidad } \\
\text { b.- Control de procesos } \\
\text { c.- Otros, especifique }\end{array}$ \\
\hline & Costos de evaluación & $\begin{array}{l}\text { Describa las categorias de costos de evaluación que maneja } \\
\text { esta entidad en sus procesos de producción } \\
\text { a.- Auditoría de la calidad } \\
\text { b.- Conservación y calibración del equipo de pruebas e } \\
\text { inspección de información de la calidad } \\
\text { c.- Otros, especifique }\end{array}$ \\
\hline & internas & $\begin{array}{l}\text { Describa las categorias de costos de prevención que maneja } \\
\text { esta entidad en sus procesos de producción. } \\
\text { a.- Desperdicios } \\
\text { b.- Repetición del trabajo, recuperación } \\
\text { c.- Otros, especifique }\end{array}$ \\
\hline & $\begin{array}{l}\text { - Costos por fallas } \\
\text { externas }\end{array}$ & $\begin{array}{l}\text { Describa las categorias de costos de prevención que maneja } \\
\text { esta entidad en sus procesos de producción } \\
\text { a.- Servicio al producto } \\
\text { b.- Retiro del producto } \\
\text { c.- Otros, especifique }\end{array}$ \\
\hline \multirow{4}{*}{$\begin{array}{l}\text { Estrategias de } \\
\text { gestión }\end{array}$} & $\begin{array}{l}\text { - Estrategias de } \\
\text { operaciones y cadenas de } \\
\text { suministros }\end{array}$ & $\begin{array}{l}\text { Describa los tipos de estrategias de gestión que maneja la } \\
\text { entidad para el mejoramiento sus operaciones en la cadena } \\
\text { de suministros. }\end{array}$ \\
\hline & $\begin{array}{l}\text { - Estrategia de costo o } \\
\text { precio }\end{array}$ & $\begin{array}{l}\text { Describa los tipos de estrategias de gestión que maneja la } \\
\text { entidad para el mejoramiento sus operaciones aplicadas a } \\
\text { costos y precios. }\end{array}$ \\
\hline & Estrategia de calidad & $\begin{array}{l}\text { Describa los tipos de estrategias de gestión que maneja la } \\
\text { entidad para el mejoramiento sus operaciones de calidad. }\end{array}$ \\
\hline & $\begin{array}{l}\text { - Estrategia de } \\
\text { velocidad en entrega }\end{array}$ & $\begin{array}{l}\text { Describa los tipos de estrategias de gestión que maneja la } \\
\text { entidad para el mejoramiento sus operaciones de velocidad } \\
\text { en entrega. }\end{array}$ \\
\hline
\end{tabular}

Fuente: elaboración propia

La población es "el conjunto de elementos que poseen características que los distinguen, para los cuales serán extensivas las conclusiones de la investigación”. En correspondencia con el estudio, la población estuvo conformada por el Ingeniero de Seguridad Industrial, el Ingeniero de Control de Calidad y el Contador Público, representantes del Central Azucarero Trujillo, S.A., quienes actuaron como informantes clave de la investigación (Silva, 2006, p. 96).

Las técnicas de recolección de datos son aquellos "procedimientos o formas particulares de obtener datos o información" (Arias, 2012, p. 67). Para este estudio se hizo uso de la entrevista estructurada aplicada a los informantes clave de la entidad (Ingeniero de Seguridad Industrial, Ingeniero de control de Calidad y el Contador Público).

Para determinar la validez del instrumento se utilizó la validez de contenido concedida por tres profesores expertos de la Universidad de Los Andes - ULA, Trujillo, como son: Doctora Walevska López, especialista en producción y en metodología de la investigación, Doctora Yosmary Durán, especialista en costos y en metodología de la investigación, Magister Arianna Barrios, especialista en metodología de la investigación. En relación a este aspecto, Méndez (2013, p. 196), señala que la validez "es el grado en que una prueba mide lo que se propone medir".

Una vez aplicada la entrevista estructurada a los informantes clave en la productividad y operatividad del Central Azucarero Trujillo S.A., la información fue sometida a un análisis de contenido mediante matrices de triangulación donde se pudieron observar las divergencias y convergencias de cada una de las respuestas de los tres sujetos informantes. La triangulación es una estrategia que puede combinar múltiples puntos de referencia para profundizar un objeto de conocimiento, tales como: triangulación de datos -sujetos informantes, tiempo y/o espacio-, investigadores, teorías, metodologías, etc. (Arias, 1999). Esta investigación aplicó una triangulación de sujetos informantes para la recolección de datos con miras a dar mayor profundidad en la obtención de información con el objetivo de enriquecer el análisis de los resultados. 
Para tal fin, se utilizó una grabadora de sonido para facilitar el registro de las respuestas de los informantes. Luego, las respuestas tuvieron el siguiente procedimiento: 1) tabulación de datos recolectados en cada una de las matrices, de acuerdo con cada uno de los objetivos; y 2) análisis e interpretación de cada resultado.

\section{PRESENTACIÓN Y ANÁLISIS DE LOS RESULTADOS}

En este apartado se presentan los resultados de la investigación y el análisis por cada una de las preguntas de las entrevistas.

Pregunta $\mathrm{N}^{\circ}$ 1: Describa las categorías de costos de prevención que maneja esta entidad en sus procesos de producción.

TABLA 5

Matriz de Triangulación 1

\begin{tabular}{|c|c|c|c|c|}
\hline \multicolumn{2}{|c|}{ Ejes de indagación } & $\begin{array}{l}\text { Ingeniero de seguridad } \\
\text { industrial }\end{array}$ & Ingeniero de control de calidad & Contador público \\
\hline \multirow{2}{*}{ 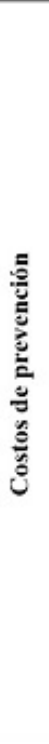 } & $\begin{array}{l}\text { Planeación de } \\
\text { la calidad }\end{array}$ & $\begin{array}{l}\text { "Si se realiza una } \\
\text { planificación de la } \\
\text { calidad antes de iniciar } \\
\text { todo proceso productivo } \\
\text { de manera tal que se } \\
\text { pueda determinar con } \\
\text { qué recursos se cuenta } \\
\text { para la producción". }\end{array}$ & $\begin{array}{l}\text { "Si existe una planificación de la } \\
\text { calidad de los productos que } \\
\text { ofrece el Central Azucarero } \\
\text { Trujillo, S.A, esto con la finalidad } \\
\text { de determinar la disponibilidad de } \\
\text { recursos y lograr la mayor } \\
\text { utilización de los insumos. La } \\
\text { planeación se realiza a través de } \\
\text { mesas de trabajo en los } \\
\text { congresillos donde participa cada } \\
\text { departamento que conforma la } \\
\text { fábrica". }\end{array}$ & $\begin{array}{l}\text { "El Central planifica los procesos } \\
\text { con anticipación con la finalidad } \\
\text { de determinar los recursos } \\
\text { necesarios para desarrollar los } \\
\text { procesos, así como aquellos que } \\
\text { hacen falta. Como las respuestas } \\
\text { tardan en llegar por parte de la } \\
\text { Corporación la planificación y } \\
\text { posterior solicitud se realizan con } \\
\text { antelación al proceso productivo". }\end{array}$ \\
\hline & $\begin{array}{l}\text { Control de } \\
\text { procesos }\end{array}$ & $\begin{array}{l}\text { "Se lleva un control de } \\
\text { procesos mediante una } \\
\text { planificación previa y } \\
\text { una vez iniciada la } \\
\text { producción se ejecuta el } \\
\text { control de procesos de } \\
\text { fabricación como tal, con } \\
\text { el fin de crear medios de } \\
\text { mejoramiento y } \\
\text { asegurarse de la } \\
\text { aplicación efectiva de la } \\
\text { planeación de la calidad". }\end{array}$ & $\begin{array}{l}\text { "La supervisión de los trabajos } \\
\text { conlleva al logro de los objetivos, } \\
\text { de alli radica el control de los } \\
\text { procesos, esto es muy importante } \\
\text { porque permite determinar qué } \\
\text { tan eficiente se está siendo en la } \\
\text { planificación de los procesos de } \\
\text { transformación". }\end{array}$ & $\begin{array}{l}\text { "Si existe una planificación de la } \\
\text { calidad de los productos que } \\
\text { ofrece el Central Azucarero } \\
\text { Trujillo S.A, esto con la finalidad } \\
\text { de determinar la disponibilidad de } \\
\text { recursos y lograr la mayor } \\
\text { utilización de los insumos. La } \\
\text { planeación se realiza a través de } \\
\text { mesas de trabajo en los } \\
\text { congresillos donde participa cada } \\
\text { departamento que conforma la } \\
\text { fábrica". }\end{array}$ \\
\hline
\end{tabular}

Fuente: elaboración propia con base en las entrevistas del estudio

Con relación a los costos de planeación de la calidad, los tres sujetos informantes clave coincidieron en que la entidad lleva a cabo una planificación de la calidad con anticipación al proceso productivo, esto con la finalidad de determinar la disponibilidad de recursos a utilizar, así como también el personal necesario para llevar a cabo los procesos productivos. Además, el Contador Público de la entidad pudo acotar que, en el caso de faltar recursos, como las respuestas tardan en llegar por parte de la Corporación, la planificación y posterior solicitud de los mismos se realizan también con antelación al proceso productivo. Cabe destacar, que la entidad sí incurre en este tipo de costos de prevención, con el propósito de planear todos los detalles referentes al proceso productivo e identificar las posibles fallas que se pudieran suscitar, así como suministrar información útil para promediar los resultados a obtener. Al respecto, Dale y Plunkett (1993), Polimeni et al. (1994), Horngren et al. (2007), destacan que en la planeación de la calidad deben incluirse todos los costos que correspondan al tiempo que invierte el personal en planear los detalles relacionados con la calidad y en traducir los requisitos del diseño del producto y de calidad del consumidor en controles específicos de manufactura en la calidad de los materiales, proceso y productos por medio de métodos, procedimientos e instrucciones formales.

En cuanto a los costos de Control de procesos, todos los informantes clave expresaron que sí se realiza un control de procesos dentro de la entidad. De un lado, el Ingeniero de Seguridad Industrial señala que esto se lleva a cabo mediante una planificación previa y una vez iniciada la producción se ejecuta el control de procesos de fabricación como tal; y por otro lado, el Ingeniero de Control de Calidad y el Contador 
Público coincidieron en que el control de procesos se realiza mediante una observación y supervisión de los mismos. Cabe mencionar que la entidad sí incurre en este tipo de costos, puesto que se vigila y se supervisa constantemente el proceso de fabricación desde el inicio, con el fin de determinar la efectividad de la planeación de la calidad para lograr la optimización de los procesos. Tal como lo señalan Dale y Plunkett (1993), Polimeni et al. (1994) y Horngren et al. (2007), al considerar que el control de procesos incluye los costos originados por el tiempo que el personal de control de calidad invierte al estudiar y analizar los procesos de fabricación con el fin de establecer medios de control y mejoramiento de la capacidad de los procesos existentes, así como proporcionar ayuda técnica al personal de producción en la aplicación efectiva de los planes de la calidad y en la iniciación y desarrollo del control de los procesos operativos de la manufactura.

Pregunta $\mathrm{N}^{\circ}$ 2: Describa las categorías de costos de evaluación que maneja esta entidad en sus procesos de producción.

TABLA 6

Matriz de Triangulación 2

\begin{tabular}{|c|c|c|c|c|}
\hline \multicolumn{2}{|c|}{ Ejes de indagación } & $\begin{array}{c}\text { Ingeniero de seguridad } \\
\text { industrial }\end{array}$ & $\begin{array}{l}\text { Ingeniero de control de } \\
\text { calidad }\end{array}$ & Contador público \\
\hline \multirow{2}{*}{ 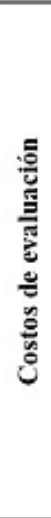 } & $\begin{array}{l}\text { Auditoria de la } \\
\text { calidad }\end{array}$ & $\begin{array}{l}\text { "Se aplican auditorias } \\
\text { mínimas únicamente para } \\
\text { evaluar el proceso y saber si } \\
\text { está dentro de los parámetros } \\
\text { impuestos por la entidad". }\end{array}$ & $\begin{array}{l}\text { "Las auditorias son poco } \\
\text { frecuentes y se realizan en su } \\
\text { mayoria por los supervisores } \\
\text { los cuales mediante una } \\
\text { evaluación determinan el } \\
\text { cumplimiento o } \\
\text { incumplimiento de los } \\
\text { parámetros de producción". }\end{array}$ & $\begin{array}{l}\text { "No se realizan } \\
\text { constantemente auditorias, sin } \\
\text { embargo, cuando se ejecutan } \\
\text { se hace como medio de } \\
\text { inspección para determinar si } \\
\text { los procesos y procedimientos } \\
\text { se están realizando a } \\
\text { cabalidad". }\end{array}$ \\
\hline & $\begin{array}{l}\text { Conservación y } \\
\text { calibración del } \\
\text { equipo de } \\
\text { pruebas e } \\
\text { inspección de } \\
\text { información de } \\
\text { la calidad }\end{array}$ & $\begin{array}{l}\text { "Si se realiza la calibración } \\
\text { de equipos ya que cuentan } \\
\text { con instrumentistas } \\
\text { especializados". }\end{array}$ & $\begin{array}{l}\text { "La calibración de los equipos } \\
\text { si se lleva a cabo por los } \\
\text { expertos en el área con los } \\
\text { cuales cuenta la fábrica, así } \\
\text { como también se incure en el } \\
\text { mantenimiento de los equipos } \\
\text { para extender un poco su vida } \\
\text { útil". }\end{array}$ & $\begin{array}{l}\text { "La calibración, } \\
\text { mantenimiento y reparación de } \\
\text { los equipos es tarea de los } \\
\text { mecánicos, ellos realizan } \\
\text { arduas actividades para evitar } \\
\text { que los equipos sufran alguna } \\
\text { falla o desperfecto". }\end{array}$ \\
\hline
\end{tabular}

Fuente: elaboración propia con base en las entrevistas del estudio

En lo que se refiere a la Auditoría de la calidad, todos los informantes clave coincidieron que la fábrica lleva a cabo este tipo de auditorías -aunque con poca frecuencia-, para evaluar si los procesos y procedimientos se están realizando a cabalidad, así como también para verificar el cumplimiento de los parámetros de producción. Lo anterior coincide con Dale y Plunkett (1993), Polimeni et al. (1994), Horngren et al. (2007), al señalar que las auditorías de la calidad constituyen costos de calidad importantes ya que están relacionados con el tiempo que emplea el personal en verificar si los procedimientos se están ejecutando en forma correcta, lo cual es un aspecto positivo para la entidad.

En relación con la Conservación y calibración del equipo de pruebas e inspección de información de la calidad, todos los informantes claves coincidieron que la empresa incurre en este tipo de costo con el propósito de realizar las respectivas medidas a las máquinas y evitar que sufran alguna falla o desperfecto durante el proceso productivo, además acotan que dicha actividad es llevada a cabo por personal de la misma fábrica como lo son los mecánicos e instrumentistas. De este modo, se evidencia que la entidad obedece a este tipo de costo al someter sus equipos a mantenimientos constantes y así evitar que se susciten fallas en el proceso productivo.

Pregunta $\mathrm{N}^{\circ}$ 3: Describa las categorías de costos de prevención que maneja esta entidad en sus procesos de producción. 
TABLA 7

Matriz de Triangulación 3

\begin{tabular}{|c|c|c|c|c|}
\hline \multicolumn{2}{|c|}{ Ejes de indagación } & \multirow{2}{*}{$\begin{array}{l}\text { Ingeniero de seguridad } \\
\text { industrial }\end{array}$} & \multirow{2}{*}{$\begin{array}{l}\begin{array}{c}\text { Ingeniero de control de } \\
\text { calidad }\end{array} \\
\text { "Si se presentan desperdicios } \\
\text { en los procesos productivos, } \\
\text { pero se trata en la medida } \\
\text { posible de hacer uso eficiente } \\
\text { de estos como por ejemplo el } \\
\text { bagazo que es utilizado como } \\
\text { combustible en las calderas". }\end{array}$} & Contador público \\
\hline 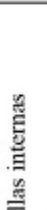 & Desperdicios & & & $\begin{array}{l}\text { "Si existe la presencia de } \\
\text { desperdicios, pero, aunque } \\
\text { estos no son de gran volumen } \\
\text { permite evidenciar la falta de } \\
\text { optimización de los procesos". }\end{array}$ \\
\hline $\begin{array}{l}\overline{\bar{w}} \\
\frac{1}{8} \\
\frac{2}{8} \\
\frac{8}{8} \\
8 \\
8\end{array}$ & $\begin{array}{l}\text { Repetición del } \\
\text { trabajo } \\
\text { (recuperación) }\end{array}$ & $\begin{array}{l}\text { "Se incurre en reprocesos } \\
\text { como consecuencia de una } \\
\text { inadecuada supervisión en } \\
\text { el proceso de fabricación, } \\
\text { esta situación no se } \\
\text { presenta con frecuencia". }\end{array}$ & $\begin{array}{l}\text { "Pocas veces se toca repetir el } \\
\text { trabajo, sin embargo, si ha } \\
\text { sucedido, pero esto ocurre por } \\
\text { fallas en los equipos por el } \\
\text { tanto uso". }\end{array}$ & $\begin{array}{l}\text { "La presencia de reprocesos es } \\
\text { muy poco frecuente y se } \\
\text { incurre más que todo cuando } \\
\text { ha ocurrido alguna falla } \\
\text { durante el proceso, de igual } \\
\text { modo se trata de evitar la } \\
\text { presencia de desperfectos de } \\
\text { cualquier tipo". }\end{array}$ \\
\hline
\end{tabular}

Fuente: elaboración propia con base en las entrevistas del estudio

En cuanto a los Desperdicios, los tres informantes clave coincidieron que la entidad sí incurre en desperdicios, debido a que las maquinarias presentan fallas durante su funcionamiento, contribuyendo a la presencia de ellos una vez culminado el proceso productivo. Los desperdicios, según Dale y Plunkett (1993), Polimeni et al. (1994), Horngren et al. (2007), suelen ser el resultado de fallas en el propio trabajo de la fábrica. El Central Azucarero Trujillo S.A. sí incurre en este tipo de costos, ya que para lograr obtener los productos bajo los parámetros de calidad establecidos, requiere la utilización de tiempos adicionales de producción en los cuales se generan desperdicios.

Con relación a la Repetición del trabajo (recuperación), los informantes clave expresaron que estos costos son recurrentes en la fábrica. Por un lado, el Ingeniero de Seguridad Industrial expresa que esto ha ocurrido como consecuencia de la incorrecta supervisión en el proceso de fabricación; por otro lado, según el Ingeniero de control de Calidad y el Contador Público los reprocesos son resultados de fallas en una o varias etapas del proceso de transformación. Se pudo constatar que la organización incurre en este tipo de costos, bien sea por inadecuadas supervisiones del proceso productivo o por fallas en los equipos durante el proceso de fabricación, incluso la mala utilización de los materiales y suministros podría contribuir a la repetición del trabajo. La recuperación o repetición del trabajo puede darse por fallas en la fabricación propiamente, tal como lo señala Polimeni et al. (1994).

Pregunta $\mathrm{N}^{\circ}$ 4: Describa las categorías de costos de prevención que maneja esta entidad en sus procesos de producción.

TABLA 8

Matriz de Triangulación 4

\begin{tabular}{|c|c|c|c|c|}
\hline \multicolumn{2}{|c|}{ Ejes de indagación } & $\begin{array}{c}\text { Ingeniero de seguridad } \\
\text { industrial }\end{array}$ & Ingeniero de control de calidad & Contador público \\
\hline \multirow{2}{*}{ 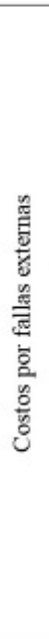 } & $\begin{array}{l}\text { Servicio al } \\
\text { producto }\end{array}$ & $\begin{array}{l}\text { "Una vez detectadas las } \\
\text { imperfecciones por el personal } \\
\text { de producción, se incurre en } \\
\text { este tipo de costo sometiendo el } \\
\text { producto inmediatamente a } \\
\text { reproceso con la finalidad de } \\
\text { hacerle las respectivas } \\
\text { correcciones de acuerdo con los } \\
\text { parametros". }\end{array}$ & $\begin{array}{l}\text { "Durante la producción se ha } \\
\text { evidenciado la presencia de } \\
\text { imperfecciones en el producto, lo } \\
\text { que obliga al gerente de área a } \\
\text { someterlo a correcciones, } \\
\text { trayendo esto como consecuencia } \\
\text { incurrir en costos adicionales". }\end{array}$ & $\begin{array}{l}\text { "En ocasiones los productos } \\
\text { han salido con } \\
\text { imperfecciones obligando } \\
\text { esta situación a incurrir en } \\
\text { los reprocesos con el fin de } \\
\text { corregir la falla y evitar } \\
\text { posibles acciones juridicas } \\
\text { por el mismo } \\
\text { inconveniente". }\end{array}$ \\
\hline & $\begin{array}{l}\text { Retiro del } \\
\text { producto }\end{array}$ & $\begin{array}{l}\text { "Si se han presentado } \\
\text { situaciones en las que se ha } \\
\text { tenido que retirar el producto } \\
\text { por incumplimiento con las } \\
\text { exigencias del cliente". }\end{array}$ & $\begin{array}{l}\text { "Aun cuando se mantiene un } \\
\text { control riguroso de los procesos, } \\
\text { en pocas ocasiones se ha } \\
\text { incurrido en este tipo de costos, } \\
\text { esto debido a que el producto ha } \\
\text { salido de la fábrica con } \\
\text { imperfecciones". }\end{array}$ & $\begin{array}{l}\text { "En ocasiones poco } \\
\text { frecuentes se ha retirado el } \\
\text { producto del mercado, por } \\
\text { incumplimiento en las } \\
\text { especificaciones como el } \\
\text { tamaño del grano y la } \\
\text { blancura del mismo, en otras } \\
\text { ocasiones se ha presentado la } \\
\text { presencia de pequeñas } \\
\text { particulas de óxido } \\
\text { generadas por la maquinaria } \\
\text { tan antigua con la que se } \\
\text { cuenta". }\end{array}$ \\
\hline
\end{tabular}


En cuanto al Servicio al producto, los tres informantes clave coincidieron que la entidad sí ha incurrido en este tipo de costos, con el propósito de realizar correcciones a los productos que han presentado imperfecciones una vez elaborados, como consecuencia de fallas no detectadas durante el proceso productivo. Con relación a este aspecto, Polimeni et al. (1994, p. 407), considera que el servicio al producto corresponde a "todos los costos aceptados por servicio al producto, directamente atribuible a la corrección de imperfecciones o pruebas especiales". Por tal motivo, al constatar imperfecciones en los productos la entidad incurre en este tipo de costo para hacer las respectivas correcciones y evitar la distribución de unidades que no cumplan con sus estándares de calidad.

En relación al Retiro delproducto, los informantes clave coincidieron en que sí se han presentado situaciones en las que ha sido necesario retirar el producto por no cumplir con los requerimientos establecidos, bien sea por indicadores inferiores de calidad o por características en cuanto al diseño; el Ingeniero de Seguridad Industrial y el Contador Público atribuyen a esta situación la desactualización en maquinaria que presenta actualmente la fábrica, mientras que el Ingeniero de Control de Calidad opina que esta situación es producto de los cierres temporales que se han suscitado en la fábrica así como de la utilización de insumos de baja calidad. Dale y Plunkett (1993), Polimeni y otros (1994), Horngren y otros (2007), argumentan que estos costos se dan por imperfecciones detectadas fuera de la empresa.

Pregunta ${ }^{\circ}$ 5: Describa los tipos de estrategias de gestión que maneja la entidad para el mejoramiento sus operaciones.

TABLA 9

Matriz de Triangulación 5

\begin{tabular}{|c|c|c|c|}
\hline $\begin{array}{c}\text { Ejes de } \\
\text { indagación }\end{array}$ & Ingeniero de seguridad industrial & $\begin{array}{l}\text { Ingeniero de control de } \\
\text { calidad }\end{array}$ & Contador Público \\
\hline $\begin{array}{l}\text { Estrategia de } \\
\text { operaciones y } \\
\text { cadena de } \\
\text { suministros }\end{array}$ & $\begin{array}{l}\text { "Se ponen en práctica medidas para } \\
\text { evitar problemas con el suministro } \\
\text { de materiales e insumos, elaborando } \\
\text { para tal efecto un inventario minimo } \\
\text { y máximo el cual permite conocer, a } \\
\text { través de indicadores de gestión, la } \\
\text { disponibilidad." }\end{array}$ & $\begin{array}{l}\text { "Si aplican estrategias para } \\
\text { corregir las debilidades de } \\
\text { manera tal que no se vuelvan a } \\
\text { presentar, elaborando un plan } \\
\text { de trabajo que conlleve a la } \\
\text { producción en el menor tiempo } \\
\text { posible con los recursos } \\
\text { disponibles." }\end{array}$ & $\begin{array}{l}\text { "Se elaboran planes de acción } \\
\text { que contribuyan al } \\
\text { fortalecimiento de las } \\
\text { operaciones dentro del Central } \\
\text { y por lo tanto conlleven a hacer } \\
\text { un mejor uso de materiales y } \\
\text { suministros con la finalidad de } \\
\text { evitar tanto el uso excesivo de } \\
\text { estos como el aumento en } \\
\text { costos de producción." }\end{array}$ \\
\hline $\begin{array}{l}\text { Estrategia de } \\
\text { costo o precio }\end{array}$ & $\begin{array}{l}\text { "Por ser una entidad publica el } \\
\text { Estado fija a nivel Nacional el } \\
\text { precio de venta del producto, con } \\
\text { base en ese precio de venta la } \\
\text { entidad establece los costos de } \\
\text { producción los cuales deben } \\
\text { proporcionar unos ingresos para } \\
\text { cubrir nomina, gastos, entre otros." }\end{array}$ & $\begin{array}{l}\text { "Se elaboran proyectos en los } \\
\text { que la producción abarque el } \\
\text { menor número de dias posible } \\
\text { con la cantidad de materia } \\
\text { prima e insumos requeridos, } \\
\text { garantizando esto una } \\
\text { producción en masa a bajos } \\
\text { costos en un corto plazo." }\end{array}$ & $\begin{array}{l}\text { "Cabe destacar que los } \\
\text { productos que ofrece la entidad } \\
\text { se encuentran regulados por el } \\
\text { Ejecutivo Nacional, por ello se } \\
\text { trabaja en función de hacer el } \\
\text { menor uso de los materiales y } \\
\text { suministros con la finalidad de } \\
\text { obtener costos de producción } \\
\text { cada vez más bajos y evitar } \\
\text { pérdidas." }\end{array}$ \\
\hline $\begin{array}{l}\text { Estrategia de } \\
\text { calidad }\end{array}$ & $\begin{array}{l}\text { "Se aplican medidas para mantener } \\
\text { y mejorar la calidad en el diseño y } \\
\text { proceso con los recursos disponibles } \\
\text { en la entidad a nivel interno, de } \\
\text { manera tal que se garantice la } \\
\text { satisfacción de los clientes al } \\
\text { brindar u ofrecer el producto en } \\
\text { excelentes condiciones." }\end{array}$ & $\begin{array}{l}\text { "Se implementan medidas que } \\
\text { vayan encaminadas a garantizar } \\
\text { la calidad en el diseño y } \\
\text { proceso de acuerdo a } \\
\text { COVENIN e INCUSA, } \\
\text { mediante un seguimiento o una } \\
\text { supervisión constante que se le } \\
\text { realiza al encargado de área, } \\
\text { siendo éste el principal } \\
\text { responsable de cumplir con los } \\
\text { parámetros de calidad." }\end{array}$ & $\begin{array}{l}\text { "Se ponen en práctica medidas } \\
\text { para ofrecer productos con la } \\
\text { mayor calidad posible, sin } \\
\text { embargo, en algunas ocasiones } \\
\text { influye la baja calidad de la } \\
\text { materia prima o incluso la baja } \\
\text { calidad en suministros por } \\
\text { escasez en la oferta; a pesar de } \\
\text { ello se hace hincapié en el } \\
\text { cumplimiento de los } \\
\text { parámetros establecidos." }\end{array}$ \\
\hline $\begin{array}{l}\text { Estrategia de } \\
\text { velocidad en la } \\
\text { entrega }\end{array}$ & $\begin{array}{l}\text { "No existen actualmente medidas de } \\
\text { velocidad en la entrega, puesto que } \\
\text { no tienen un cronograma } \\
\text { establecido para el despacho del } \\
\text { producto." }\end{array}$ & $\begin{array}{l}\text { "No cuentan con estrategias de } \\
\text { velocidad en la entrega del } \\
\text { producto ya que no existe } \\
\text { incentivo en los trabajadores } \\
\text { para producir con rapidez ni la } \\
\text { debida supervisión que asegure } \\
\text { el cumplimiento de dicha } \\
\text { estrategia." }\end{array}$ & $\begin{array}{l}\text { "Esta estrategia no se aplica, } \\
\text { debido principalmente a los } \\
\text { pasos burocráticos que sufren } \\
\text { los procesos de venta en la } \\
\text { fäbrica, puesto que se debe } \\
\text { esperar que la Corporación } \\
\text { apruebe la orden de venta." }\end{array}$ \\
\hline
\end{tabular}

Fuente: elaboración propia con base en las entrevistas del estudio

Con respecto a la Estrategia de operaciones y cadena de suministros, todos los informantes clave afirmaron que el Central Azucarero Trujillo S.A., sí aplica esta estrategia llevando a cabo, tanto un control de la 
disponibilidad existente de materiales y suministros para prever su agotamiento, como de reducción del uso excesivo de estos. De este modo, se establece la puesta en práctica de esta estrategia lo que conlleva a la obtención de la eficiencia en las operaciones, es decir, el buen uso y manejo de sus recursos para lograr los objetivos planteados. Esto coincide con Chase y Jacobs (2014), al señalar que las estrategias de operaciones y cadena de suministros "se ocupa de establecer las políticas y planes generales para utilizar los recursos de una entidad, y debe estar integrada a la estrategia corporativa, siendo uno de los principales enfoques dentro de esta estrategia la eficacia de las operaciones" (Chase \& Jacobs, 2014, p. 22).

Con relación a la Estrategia de costo o precio, los informantes clave coincidieron que el precio de venta del producto que fábrica la entidad no es fijado en función de los costos de producción, puesto que es el Ejecutivo Nacional quien fija los precios de venta al consumidor, sin embargo, se trata en la medida de lo posible de disminuir los costos de producción para que la entidad pueda cubrir todos los demás costos y gastos para evitar pérdidas. Al respecto, Chase y Jacobs $(2014$, p. 22), plantean que "la entidad debe ser un productor con costos bajos, aunque esto no siempre garantice rentabilidad y éxito”.

En cuanto a la Estrategia de calidad, los informantes clave coinciden al afirmar que la entidad basa sus procesos en lo establecido por las normas COVENIN e INCUSA (2007), es allí donde se exponen los parámetros los cuales deben cumplir para obtener la mejor calidad en sus productos; y aunque la fábrica lleva a cabo medidas que contribuyen a obtener calidad en los diseños y procesos, existen factores externos a ésta como la falta de oferta de materiales y suministros de calidad que inciden de manera significativa en la calidad del producto resultante, y a pesar de que el personal de área conoce la situación existente reconoce que no debe rechazar tales suministros aun cuando estos no cumplan las condiciones necesarias.

Con respecto a la Estrategia de velocidad en la entrega, los tres informantes clave aseguran que no se puede dar cumplimiento a este tipo de estrategia. El Contador Público afirmó que la fábrica no cuenta con maquinaria que permita fomentar la rapidez en los procesos, que esta estrategia implicaría aumentar el personal fijo en el área de ventas, y por último, que se deben tener en cuenta los pasos burocráticos por los que deben pasar los procesos de ventas para que finalmente la Corporación Central apruebe la orden de venta del producto. Mientras que el Ingeniero de Control de Calidad y el Ingeniero de Seguridad Industrial aseguran que los factores que impiden la aplicación de esta estrategia son la falta de incentivo de los trabajadores para acelerar el proceso productivo y la falta de planificación para el despacho del producto. En este sentido, no aplica. Aspecto desfavorable para el Central Azucarero S.A., ya que según Chase y Jacobs (2014) mientras más rápido se fabrique y entregue el producto mayor será la satisfacción del cliente.

Finalmente se formula la siguiente pregunta: ¿Utiliza esta entidad la información de los costos de calidad en el establecimiento de estrategias de gestión? Los informantes clave coincidieron al expresar que la información que proporcionan los costos de calidad se trata de usar en el establecimiento de las estrategias de gestión, sin embargo, ellos acotan que principalmente por la cantidad de procesos burocráticos que se llevan a cabo estas medidas no pasan de ser una propuesta a la alta dirección.

Considerando que las estrategias de gestión deben estar basadas en los siguientes aspectos según Betancourt (2002) y Chase y Jacobs (2014): satisfacción de los clientes, de los empleados y del entorno de la entidad; la mejora continua; y ser reconocidos como líderes en determinados aspectos. Seria errado basar las estrategias de gestión en percepciones y opiniones internas de la empresa, ya que los principales factores que dan vida a la entidad son los clientes y de ellos es que se conoce el impacto que los productos o servicios puedan generar; siendo los costos de calidad uno de los primordiales aspectos a tomar en cuenta para el establecimiento de dichas estrategias. 


\section{CONCLUSIONES Y RECOMENDACIONES}

El análisis de los costos de calidad y las estrategias de gestión en el Central Azucarero Trujillo S.A., reveló que se aplican los costos de calidad mencionados por los autores, pero no se aplican todas las estrategias de gestión, debido a que dejan por fuera la eficacia de las operaciones, la cual es crucial para la disminución de costos, para el incremento de la productividad empresarial y para la satisfacción del cliente. Al respecto, Hugo, Barrios y Martínez (2018), consideran que la eficiencia de las operaciones depende de estrategias que optimicen el proceso productivo y que al mismo tiempo maximice el valor para el cliente.

En términos específicos, en el Central Azucarero Trujillo, S.A., sí incurren en costos de calidad porque lleva a cabo actividades que planifican, mantienen y evalúan los niveles de calidad adecuados, siendo necesarios por cuanto permite evitar la pérdida futura por desperfectos en el producto. No obstante, en algunas ocasiones se presentan desperfectos, lo que indica la necesidad de una revisión de las políticas de prevención para evitar la presencia de otros tipos de costos que a futuro repercutan en la pérdida de la capacidad productiva y operativa de la entidad. En este sentido, se recomienda hacer énfasis en la revisión constante de los procesos, desde que se compra la materia prima hasta la venta de los productos a los clientes.

En lo que respecta a los costos de evaluación, se realizan auditorías de la calidad pero con poca frecuencia, sin embargo, esto contribuye a la elaboración de informes orientados hacia propuestas de mejora continua de los procesos y procedimientos dentro de la entidad, tomando en cuenta los recursos con que cuenta, por lo tanto se recomienda la realización de auditorías más exhaustivas para detectar deficiencias y oportunidades de mejora, que permitan la proyección de la entidad y de igual modo buscar los mecanismos de fortalecimiento de los procesos productivos. En cuanto a la conservación y calibración del equipo de pruebas en inspección de información de la calidad, los técnicos, mecánicos y especialistas de la fábrica hacen revisiones constantes con el fin de constatar las fallas y evitar la presencia de valores fuera de lo normal, se recomienda seguir con este tipo de actividades para asegurar el uso correcto de los equipos y evitar que estos se dañen e impidan la obtención de la evidencia ante pruebas realizadas a la calidad del producto.

En cuanto a los costos por falla internas, están presentes en los procesos de la fábrica, principalmente por averías en la maquinaria y los equipos, generando desperdicios, reprocesos y costos por suministros. En este sentido, la entidad debe hacer lo posible para reducir los desperdicios, reprocesos y costos por suministros, por lo tanto, se recomienda evitar la sobrecarga del proceso productivo ya que la maquinaria al ser obsoleta puede presentar averías y detección del proceso lo cual puede conllevar a la pérdida parcial o total de la producción en proceso; asimismo, se debe solicitar constantemente al departamento de compras que realice la requisición de materiales y suministros de calidad adecuada.

Los costos por fallas externas en el central Azucarero S.A., se presentan con baja frecuencia. El producto no posee garantía, por lo que es necesario que la entidad ofrezca a sus clientes la posibilidad de dar a conocer sus opiniones con respecto al producto mediante buzones de sugerencias y/o la aplicación de encuestas, esto coadyuvaría al conocimiento de las debilidades y fortalezas en opinión de sus clientes, logrando poder tomar medidas de mejoramiento continuo de los procesos y estrategias dentro del Central Azucarero S.A. Por otro lado, no se ha incurrido en costos por servicios al producto cuando se ha descubierto imperfecciones después de salir al mercado, así como tampoco se han presentado demandas con respecto a imperfecciones del producto.

En cuanto a la determinación de la participación de los costos de calidad en el establecimiento de estrategias de gestión, el Central Azucarero Trujillo, S.A. maneja estrategias de gestión orientadas al mejoramiento continuo de la entidad, aprovechamiento de los recursos disponibles, tratando de mantener y -en lo posibleaumentar su productividad.

La estrategia de operaciones y cadena de suministros y la estrategia de costos o precio, están estrechamente ligadas debido a que, dependiendo del buen uso de los materiales y suministros y la eficiencia en las operaciones, la entidad puede manejar costos acordes y evitar, de esta manera, la pérdida de la capacidad 
operativa por no poder cubrir sus gastos. En este sentido, la entidad debe fortalecer estas estrategias a través del establecimiento de políticas, tales como: mayor participación en la toma de decisiones en cuanto a requisición y adquisición de materiales y suministros; ello con el fin de contribuir a la adquisición de materia prima de calidad óptima, de igual manera se debe evitar la detección o retraso del proceso.

En cuanto a la estrategia de velocidad en la entrega, la falta de inversión en maquinaria con tecnología de punta es indispensable para su aplicación, ya que esto facilita la rapidez para la fabricación y entrega del producto, así como también se estaría en la capacidad de ofrecer productos diferentes e innovadores lo cual a su vez aumentaría la productividad de la entidad.

Finalmente, se constató que el Central Azucarero Trujillo, S.A. no maneja la información reflejada en los costos de calidad para el establecimiento de estrategias de gestión, lo cual se vuelve indispensable, debido a que las cuatro categorías de los costos sirven como indicadores para fortalecer las distintas actividades de la fábrica. En este sentido, se plantea una propuesta que facilite comprender la participación que pueda tener la información que proporcionan los costos de calidad con respecto a las estrategias de gestión llevadas a cabo en el Central Azucarero Trujillo, S.A., con el propósito de fortalecer su productividad y operatividad. Para lograr la conexión óptima entre estas variables, las entidades requieren seguir una rigurosa planificación, organización, dirección y control de todas las operaciones llevadas a cabo antes, durante y después de los procesos productivos, manteniendo una retroalimentación continua, es decir, comparando la evolución de la entidad a través del tiempo, y corrigiendo de esta manera aquellas fallas que se pudieran estar presentando en la entidad.

La ventaja que se obtiene en cuanto a la utilización de la información suministrada por los costos de calidad en el establecimiento de las estrategias de gestión, es que le permite a la entidad identificar los puntos débiles, y en consecuencia puede tomar los correcticos para el fortalecimiento de los sistemas operativos, a través, de la toma de decisiones acertadas que a su vez contribuyen al máximo aprovechamiento de los recursos de la entidad.

Por ello se presenta una matriz explicativa que relaciona el impacto de los costos de calidad con las estrategias de gestión en el Central Azucarero Trujillo, S.A., de acuerdo con los aportes de Horngren et al. (2007), Vesga (2013), Cuervo (2000), Dale y Plunkett (1993), Polimeni et al. (1994), Betancourt (2002) y Chase y Jacobs (2014). Con la aproximación teórica de este estudio la entidad puede identificar las estrategias de gestión que deben implementar y las que deben fortalecer, haciendo énfasis en la información que arroja cada una de las categorías de los costos de calidad y así poder tomar las mejores decisiones con base en los procesos comparativos llevados a cabo entre la información suministrada y las estrategias de gestión.

Se recomienda que las estrategias de gestión en el Central Azucarero Trujillo S.A., se fundamenten en los siguientes aspectos: satisfacción de los clientes, empleados y entorno de la entidad; la mejora continua; y el reconocimiento como líderes. Por lo tanto, las estrategias de gestión deben basarse, no sólo en la percepción y opiniones internas ya que los principales factores que dan vida a la entidad son los clientes y de ellos es que se conoce el impacto que generan los productos y/o servicios.

En este orden de ideas, los costos de calidad fundamentan las estrategias de gestión debido a que muestran de manera detallada los costos incurridos en la obtención y aseguramiento de la calidad, tomando en cuenta la materia prima utilizada, los insumos y la satisfacción que el cliente experimenta al usar los productos. Dentro de sus estrategias de gestión, el Central Azucarero Trujillo, S.A. debe tomar la opinión de clientes, obreros y empleados de la alta gerencia que permitan la mejora continua de los procesos y el crecimiento de la productividad.

\section{Agradecimientos}

Este artículo es uno de los resultados de la investigación ejecutada con financiamiento del CDCHTA-ULA a través del proyecto NURR-H-591-16-09-F. 


\section{Referencias}

Arango, L. (2009). Importancia de los costos de la calidad y no calidad en las empresas de salud como herramienta de gestión para la competitividad. Revista Escuela Administración y Negocios EAN (online), 67, 75-94. Consulta realizada el: 15 de abril de 2019. Disponible en: http://www.scielo.org.co/scielo.php? script $=$ sci_arttext\&pid $=$ S0120-81602009000300006

Arias, F. (2012). El proyecto de investigación: introducción a la metodología cientifica, 6a ed. Caracas: Editorial Episteme.

Arias, M. (1999). La triangulación metodológica: sus principios, alcances y limitaciones. Disponible en: https:// www.uv.mx/mie/files/2012/10/Triangulacionmetodologica.pdf Consultado el: 15/02/2019.

Betancourt, J. (2002). Gestión estratégica: navegando hacia el cuarto paradigma, 3a ed. Porlamar.

Chase, R., \& Jacobs, R. (2014). Administración de operaciones: producción y cadena de suministros. McGraw-Hill Education, 13 ed. México D.F.

Cuervo, M. (2000). La calidad y sus costos como factor de competitividad empresarial. Revista Legislación del contador, n. 4.

Dale, B., \& Plunkett, J. (1993). Los costos en la calidad. México DF: Grupo Editorial Iberoamérica.

Hernández, H., Barrios, I., \& Martínez, D. (2018). Gestión de la calidad: elemento clave para el desarrollo de las organizaciones. Revista Criterio Libre, 16(28), 179-195. Disponible en: https://revistas.unilibre.edu.co/ index.php/criteriolibre/article/view/2130/1621

Horngren, C., Datar, S., \& Foster, G. (2007). Contabilidad de costos. Un enfoque gerencial. 12 ed. México DF: Pearson Education.

INCUSA (2007). Manual de calidad y medio ambiente. Disponible en: http://www.incusa.es/documents/ PCalidadIncusa.pdf. Consultado el: 14 de abril 2018

ISO 9000:2015. Sistemas de gestión de la calidad. Documento en línea. Disponible en: https://www.iso.org/obp/ui/ \#iso:std:iso:9000:ed-4:v1:es. Consultado el 14 de abril 2018.

Marbán, R. (2005). Principales estrategias de gestión de la calidad desarrolladas por las almazaras cooperativas amparadas en la Denominación de Origen Montes de Toledo. Revista de economía pública, social y cooperativa, 51, 185-210. Disponible en https://dialnet.unirioja.es/servlet/articulo?codigo $=1183483$

Méndez, C. (2013). Metodología, diseño y desarrollo del proceso de investigación con énfasis en ciencias empresariales, 4a ed. México DF: Editorial Limusa.

Polimeni, R., Fabozzi, F., Adelberg, A., \& Kole, M. (1994). Contabilidad de costos, 3a ed. Bogotá: McGraw-Hill.

Ramírez, D. (2013). Contabilidad Administrativa, 9a ed. México DF: McGraw-Hill.

Silva, J. (2006). Metodología de la investigación: elementos básicos. Caracas: Colegial bolivariana.

Sociedad Americana para la Calidad - ASQ (2017). Filosofía de la calidad. Conceptos y terminología según la ASQ. Disponible en: http://calidadparalagastronomia.blogspot.com/2017/09/12-conceptos-y-terminologia-segunla-asq.html.Consultado el: 30/03/2018

Vesga, J. (2013). Cultura organizacional y sistemas de gestión de la calidad: una relación clave en la gestión de las instituciones de educación superior. Revista Guillermo de Ockham, 11(2), 89-100. Consulta realizada el 16 de abril de 2019.

\section{Notas}

* Artículo de investigación científica.

Licencia Creative Commons CC BY 4.0 